\title{
Agricultural wastes as a low cost adsorbents for the removal of Acid Blue 92 dye: A Comparative study with Commercial activated carbon.
}

\author{
R. Ram Prasath, P. Muthirulan and N. Kannan* \\ Centre for Research and Post-Graduate Studies in Chemistry Ayya Nadar Janaki Ammal College(Autonomous), \\ Sivakasi - 626124 Tamil Nadu, India
}

\begin{abstract}
In the present study, activated carbons of Eichornea crasssipes(EC), Sugarcane bagassae(SB), Tea waste(TW) and Guava leaf(GL) were prepared from agricultural wastes and used as an adsorbents for the removal of Acid Blue 92 (AB92) dye from aqueous solution. The effects of $\mathrm{pH}$, adsorbent dosage, initial dye concentration and contact time on the extent removal of AB92 has been studied by Batch adsorbtion method. The Langmuir and Freundlich isotherm models were applied for the present systems and the Langmuir model was applied to the equilibrium data better. The kinetic data followed the first-order kinetics determined from the Natarajan-Khalaf isotherm, Lagergren isotherm and Bhattacharya Venkobachar isotherm. The intraparticle diffusion was also measured to determine the porousities of the carbons and the boundary effect of the carbons on the adsorption of AB92. Effect of particle size of adsorbents and the thermodynamic parameters of adsorbents can also analysed. The desorption was also studied. From the data GUC has the more relative adsorption capacity and the ECC has the lesser among the above charcoal.
\end{abstract}

Keywords: Eichornea crasssipes; Sugarcane bagassae; Tea waste ; Guava leaf ; Low cost adsorbent; Adsorption capacity; Acid Blue 92; Adsorption kinetics

\section{Introduction}

The studies on the environmental pollution and its removal are noted on a few decades. The reason for this is the deterioration of both qualitative and quantitative nature of the existing natural resources caused by the discharge of untreated effluents from industries and urban agglomerates[1]. The quality of ground water is very much important, as it is being depleted and being contaminated in many parts of the world. Industrial effluents from the dye manufacturing industries, textiles, printing, paper, pulp and other dyeing industries are highly coloured. In order to provide a sustainable environment for aquatic life, wastewater treatment becomes highly essential. The methods of purifying water and industrial wastewater are largely traditional. In recent years, many methods of water purification have been introduced, such as activated sludge process, precipitation method, ultrafiltration, ion-exchange method, reverse osmosis, electro dialysis, solvent extraction, photooxidation, adsorption, etc. [1-2], particularly in the field of industrial water and wastewater treatment. Adsorption is widely employed for the removal of dyes and colour. Activated carbon (AC) adsorption has become the standard method of water and wastewater treatment. Apart from AC, a number of other low cost adsorbent materials have also been employed [3]. Attempts have been made to develop the AC from agricultural and industrial wastes. Preparation of ACs from a wide range of agrowastes for water purification has recently been reported [3]. Natural adsorbents are also used as adsorbents for the water and wastewater treatment [4]. Despite its prolific use in water and wastewater industries, CAC remains an expensive material. This has led to a search for low cost materials as alternative adsorbent materials.

Waste material management and reuse of wastes are the recent topics of interest. The natural adsorbent materials such as Eichornea Crassipes(ECC), Sugarcane Bagassae(SBC), Tea Waste(TWC) and Guava(GLC) are effectively used in the removal of toxic substances like heavy metal ions, pesticides, dyes, acids, organic compounds and anions [5]. In the literature, several other non-conventional adsorbent materials like suspended particles / sediments of river, canola meals, serpentine, spend bleaching earth from oil industry, water hyacinth and human hair have been reported as low cost adsorbents in wastewater treatment processs. To the best of my knowledge, there has no reports for the removal of AB92 dye on ECC,SBC,TWC and GLC as adsorbents.

The present work aims at assessing the ability of Eichornea Crassipes(EC), Sugarcane Bagassae(SB), Tea Waste (TW) and Guava(GU) as economically attractive low cost adsorbents for the removal of AB92 and also to study the kinetics of removal of AB92. The effect of various process parameters on the extent of removal of AB92 was investigated, to optimise the process parameters. Various adsorption isotherms and kinetic equations were adopted to study the nature of adsorption process. 


\subsection{Preparation of Charcoal}

\section{Experimental Methods}

CAC was procured from E Merck (India). AB supplied by BDH (India) was used as an adsorbate as such. Double Distilled (DD) water was used for preparing all the solutions and reagents. Thermostatic incubator shaker (Neolab, India) was used to maintain the temperature $\left(30 \pm 1^{\circ} \mathrm{C}\right)$. Raw materials for the preparation of ACs such as Eichornea Crassipes(EC), Sugarcane Bagassae(SB), Tea Waste(TW) and Guava(GU) were collected locally, washed, dried and cut into small pieces. The raw materials were carbonised (at $300-400^{\circ} \mathrm{C}$ ) in Muffle furnace and thermally activated with $\mathrm{NaHCO}_{3}$ (at $700-900^{\circ} \mathrm{C}$ ) to produce $\mathrm{CO}_{2}$ inert atmosphere at high temperature, which avoids ash formation. It was digested with $4 \mathrm{~N} \mathrm{H}_{2} \mathrm{SO}_{4}$ solution (at $80^{\circ} \mathrm{C}$ for $2 \mathrm{~h}$ ), washed, dried and sieved into discrete particle size (Jayant sieve, India). Adsorbent samples were thermally activated at $120^{\circ} \mathrm{C}$ for $2 \mathrm{~h}$.

\subsection{Adsorption Studies}

A stock solution of AB92 (500 $\left.\mathrm{mg} \mathrm{L}^{-1}\right)$ was prepared and suitably diluted to the various required initial concentrations. Adsorption experiments were carried out at room temperature $\left(30 \pm 1^{\circ} \mathrm{C}\right)$ under batch mode [7]. The concentrations of the dye solutions before and after adsorption were estimated by measuring optical density (OD) at $554 \mathrm{~nm}\left(\lambda_{\max }\right)$ with the help of Systronics spectrophotometer (Model: SL-105, India) and then interpolated into the standard curve. Exactly $50 \mathrm{~mL}$ of $\mathrm{AB} 92$ solution of known initial concentration $\left(\mathrm{C}_{\mathrm{i}}\right)$ was shaken at the constant agitation speed $(200 \mathrm{rpm})$ with required dose of adsorbent of a fixed particle size $(90$ micron) for a specific period of contact time. The initial $\mathrm{pH}$ of the dye solution was adjusted to the required value by adding either $1 \mathrm{~N} \mathrm{HCl}$ or $1 \mathrm{~N} \mathrm{NaOH}$ solution. Initial $\mathrm{pH}$ values of $\mathrm{AB} 92$ solutions were noted with digital pen $\mathrm{pH}$ meter (Hanna instruments, Portugal). After equilibration, the final concentration $\left(\mathrm{C}_{\mathrm{f}}\right)$ of $\mathrm{AB} 92$ was measured spectrophotometrically. The values of percentage removal and the amount of AB92 adsorbed were calculated by using following relationships:

\% removal $=\left[\left(\mathbf{C}_{\mathbf{i}}-\mathbf{C}_{\mathbf{f}}\right) / \mathbf{C}_{\mathbf{i}}\right] \times \mathbf{1 0 0}$

Amount adsorbed $\left(q_{e}\right)=\left(C_{i}-C_{f}\right) / m$

where $C_{i}=$ initial concentration $(\mathrm{ppm}) ; \mathrm{C}_{\mathrm{f}}=$ final concentration $(\mathrm{ppm}) ; \mathrm{m}=$ mass of adsorbent $\left(\mathrm{g} \mathrm{L}^{-1}\right)$. Control experiments were carried out and the average values of duplicate runs were obtained and analysed (Error: $\pm 1-2 \%$ for percentage removal and $\pm 0.005-0.01 \mathrm{mg} \mathrm{g}^{-1}$ for amount adsorbed).

\subsection{Effect of initial concentration}

\section{Results and discussion}

The adsorption experiments have been carried out at different experimental conditions and the results obtained are discussed below Table 1. The effect of initial concentration of AB92 on the extent of removal of AB92 (in terms of percentage removal and amount adsorbed) on various adsorbents(CAC,ECC,SBC,TWC and GLC) were studied and the results are shown in Figure 1. The percentage removal is found to decrease exponentially, while the amount of AB92 adsorbed increases exponentially with the increase in initial concentration of AB92. This indicates a decrease in adsorption, which is attributed due to the lack of available active sites required for the high initial concentration of AB. Similar results have been reported in literature on the extent of removal of dyes, metal ions and carboxylic acids[8]. The optimum initial concentration of $A B$ solution was fixed for various adsorption systems Table 1.

\subsection{Adsorption isotherm}

The adsorption data have been analysed with the help of the following linear forms of Freundlich and Langmuir isotherms [9]:

Freundlich isotherm:

Langmuir isotherm:

$$
\log q_{e}=\log K+(1 / n) \log C_{e}
$$

$$
\left(\mathbf{C}_{\mathrm{e}} / \mathbf{q}_{\mathrm{e}}\right)=\left(1 / \mathbf{Q}_{\mathbf{0}} \mathbf{b}\right)+\left(\mathrm{C}_{\mathrm{e}} / \mathbf{Q}_{\mathbf{0}}\right)
$$

where $\mathrm{K}=$ adsorption capacity $\left(\mathrm{mg} \mathrm{g}^{-1}\right) ;(1 / \mathrm{n})=$ order of adsorption ; $\mathrm{q}_{\mathrm{e}}$ is the amount of $\mathrm{AB} 92$ adsorbed per unit mass of adsorbent $\left(\mathrm{mg} \mathrm{g}^{-1}\right) ; \mathrm{C}_{\mathrm{e}}$ is the equilibrium concentration of $\mathrm{AB} 92(\mathrm{ppm}) ; \mathrm{Q}_{\mathrm{o}}$ is the mono-layer (maximum) adsorption capacity $\left(\mathrm{mg} \mathrm{g}^{-1}\right)$ and $\mathrm{b}$ is Langmuir constant related to energy of adsorption $\left(\mathrm{L} \mathrm{mg}^{-1}\right)$

The values of Freundlich and Langmuir constants have been obtained respectively from the linear correlation between the values of (i) $\log \mathrm{q}_{\mathrm{e}}$ and $\log \mathrm{C}_{\mathrm{e}}$ and (ii) $\left(\mathrm{C}_{\mathrm{e}} / \mathrm{q}_{\mathrm{e}}\right)$ and $\mathrm{C}_{\mathrm{e}}$. The values of adsorption isotherm constants along with the correlation co-efficients are presented in Table 2. The results are also shown in Fig. 2 and Fig. 3.

Langmuir and Freundlish adsorption isotherms indicates that all the carbons possesses monolayer adsorption process and higher the $\mathrm{Q}_{0}$ value of GUC indicates maximum adsorption capacity than other carbons. 
Further, the essential characteristics of the Langmuir isotherm can be described by a Separation factor, $\mathrm{R}_{\mathrm{L}}$, which is defined by the following equation $[10,11]$ :

$$
\mathbf{R}_{\mathrm{L}}=\left[\mathbf{1} /\left(\mathbf{1}+\mathbf{b C}_{\mathbf{i}}\right)\right]
$$

where $C_{i}$ is the initial concentration of dye and b is the Langmuir constant related to energy of adsorption ( $L$ $\mathrm{mg}^{-1}$ )

The value of separation factor, $\mathrm{R}_{\mathrm{L}}$ indicates the nature of the adsorption process [12] as given below:

\section{$R_{L}$ value Nature of adsorption}

$\mathrm{R}_{\mathrm{L}}>1 \quad$ Unfavourable

$\mathrm{R}_{\mathrm{L}}=1 \quad$ Linear

$0<\mathrm{R}_{\mathrm{L}}<1 \quad$ Favourable

$\mathrm{R}_{\mathrm{L}}=0 \quad$ Irreversible

In the present study, the values of $\mathrm{R}_{\mathrm{L}}$ (Table 2) are observed to be in the range of zero to one i.e., fraction (0.0071149-0.01112), which indicate that the adsorption process is favourable for all these adsorbents.

\subsection{Effect of contact time}

The effect of contact time on the extent removal of AB92 dye on various adsorbents such as CAC, ECC, SBC, TWC and GUC was studied by keeping the other parameters as constant. The removal of AB92 by these adsorbents is found to increase exponentially and reach a maximum value with increase in contact time. Afterwards, it becomes constant and decreases in some cases. The decrease may be due to the desorption process of $\mathrm{AB} 92$. The relative increase in the extent of removal of $\mathrm{AB} 92$ after 60 min., of contact time is not significant and hence it is fixed as the optimum contact time. Similar results have been reported in literature for the removal of dyes [13 - 20]. In batch type adsorption systems, mono-layer of adsorption (dye) is normally formed on the surface of adsorbent and the rate of removal of adsorbate (dye) species from aqueous solution is controlled primarily by the rate of transport of the adsorbate species from the exterior / outer sites to the interior sites of the adsorbent particles.

\subsection{Kinetics of adsorption}

The kinetics and dynamics of adsorption of AB92 on various adsorbents have been studied by applying the various first order kinetic models proposed by Natarajan-Khalaf, Lagergren and Bhattacharya-Venkobachar equations.

Natarajan and Khalaf equation

Lagergren equation

$$
\log \left(C_{i} / C_{t}\right)=(k / 2.303) t
$$

$$
\log \left(q_{e}-q_{t}\right)=\log q_{e}-(k / 2.303) t
$$

Bhattacharya and Venkobachar equation

$$
\log [1-U(T)]=-(k / 2.303) t
$$

where, $C_{i}$ and $C_{t}$ are the concentrations of AB92 at time zero and time $t$ respectively $\left(\mathrm{mg} \mathrm{L}^{-1}\right)$ and $q_{e}$ and $q_{t}$ are amounts of $\mathrm{AB} 92$ adsorbed at equilibrium time and time $\mathrm{t}$ respectively $\left(\mathrm{mg} \mathrm{g}^{-1}\right)$

$$
\mathbf{U}(\mathbf{T})=\left[\left(\mathbf{C}_{\mathbf{i}}-\mathbf{C}_{\mathbf{t}}\right) /\left(\mathbf{C}_{\mathbf{i}}-\mathbf{C}_{\mathrm{e}}\right)\right]
$$

where, $\mathrm{C}_{\mathrm{e}}=$ equilibrium concentration of $\mathrm{AB} 92$ and $\mathrm{k}=$ first order rate constant $\left(\mathrm{min}^{-1}\right)$

The values of (i) $\log \left(C_{i} / C_{t}\right)$, (ii) $\log \left(q_{e}-q_{t}\right)$ and (iii) $\log [1-U(T)]$ are linearly correlated with time $(\mathrm{t})$ and the results are shown in Figure 5-7. The values of first order rate constant and correlation coefficient (r-value) are given in Table 2. All the linear correlations are found to be statistically significant, indicating the applicability of these kinetic equations and the first order nature of the adsorption process of AB92 on these adsorbents.

The k-value obtained from Lagergren equation for all the adsorbents are found to be almost equal with the value obtained from Natarajan Khalaf, Lagergren and Bhattacharya and Venkobachar equation. Hence, any one of these kinetic equations could be used in future to calculate k-value for the adsorption of dyes. Based on the high r-values, which are close to unity, it is concluded that the Lagergren equation is applicable to the kinetics of adsorption of AB92.

\subsection{Intra particle diffusion model}

The adsorbate species are most probably transported from the bulk of the solution into the solid phase through intra particle diffusion / transport process, which is often the rate limiting step in many adsorption processes, especially in a rapidly stirred batch reactor. The possibility of intra particle diffusion process was explored by using the Weber and Morris intra particle diffusion model [21]:

$$
\mathbf{q}_{\mathrm{t}}=\mathbf{k}_{\mathrm{p}} \mathbf{t}^{1 / 2}+\mathbf{C}
$$

where $\mathrm{q}_{\mathrm{t}}=$ the amount of $\mathrm{AB}$ adsorbed at time $\mathrm{t} ; \mathrm{C}=$ intercept; $\mathrm{k}_{\mathrm{p}}=$ intra particle diffusion rate constant 
The values of $\mathrm{q}_{\mathrm{t}}$ are found to be linearly correlated with values of $\mathrm{t}^{1 / 2}$. The $\mathrm{k}_{\mathrm{p}}$ values were calculated by using correlation analysis showing in Table 3 and Figure 8 . The r-values are found to be close to unity, indicating the application of this model. This reveals the presence of intra particle diffusion process [36]. The calculated values of $\mathrm{k}_{\mathrm{p}}$ for adsorbents ( $\mathrm{mg} \mathrm{g}^{-1} \mathrm{~min}^{-1 / 2}$ ) are ECC (0.015), SBC (0.018), TWC (0.017) and GUC (0.026). This result indicates that the GUC is more porous than the other adsorbents. The large values of intercept (Table 4) give an idea about the boundary layer thickness i.e. larger the intercept, greater is the boundary layer effect [22]. The intercept $(\mathrm{C})$ value is maximum in GUC $(0.360)$ and minimum in ECC $(0.307)$ for adsorbents other than CAC, indicating the boundary layer effect is maximum in GUC and minimum in ECC.

The correlation of the values of $\log (\%$ removal) and log (time) also resulted in linear relationship. This indicates that the process of intra particle diffusion is also taking place in these adsorption system (Table 3). The divergence in the values of slope from $0.008(\mathrm{~min} .-\max .=0.017-0.025)$ indicates the presence of intra particle diffusion process as one of the rate limiting steps, besides many other processes controlling the rate of adsorption, all of which may be operating simultaneously [23].

\subsection{Effect of dose}

The effect of dose of adsorbent on the amount of AB92 adsorbed has been studied (Table 1) and the results are given in Figure 9. The equilibrium value of amount adsorbed $\left(\mathrm{q}_{\mathrm{e}}\right)$ is observed to decrease exponentially with increase in dose of adsorbent. The value of percentage removal of AB92 (Table 1) increase exponentially with increase in dose of adsorbent. This may be due to the increase in availability of surface active sites resulting from the increased dose and conglomeration of the adsorbent. The amount of dye (AB92) adsorbed is observed to vary exponentially in accordance with the fractional power term of the dose of adsorbent i.e., $(\text { dose })^{-\mathrm{n}}$; where $\mathrm{n}=$ fraction. The $\mathrm{n}$-value $(\mathrm{r}$-value) is $\mathrm{ECC}=0.9874, \mathrm{SBC}=0.9654, \mathrm{TWC}=$ 0.9959 and GUC $=0.9752$. The plots of $\log q_{\mathrm{e}} v s \log$ (dose) are found to be linear. This suggests that the adsorbed species (dye) may either block the access to the internal pores or causes particles to aggregate and there by resulting in the availability of active sites for adsorption. Similar observations have been noticed for the removal of dyes [24].

\subsection{Effect of initial pH}

The effect of initial $\mathrm{pH}$ of the dye solution on the amount of dye (AB92) adsorbed has been studied by varying the initial $\mathrm{pH}$, under constant conditions of other process parameters (Table1). The optimum $\mathrm{pH}$ value is fixed as 4.6 (ECC), 5.2 (SBC), 5.1 (TWC) and 5.3 (GUC). The results are shown in Figure 10. The increase in initial $\mathrm{pH}$ almost linearly increases the amount of AB92 adsorbed $(\mathrm{r}=0.8006-0.9566)$. The change in initial $\mathrm{pH}$ values of dye solution significantly affect the adsorption characteristics of basic dye indicating that removal of $\mathrm{AB}$ (basic dye) is enhanced by basic solution. This result is in harmony with the literature reports for basic dye [25].

\subsection{Effect of particle size}

The amount of AB92 adsorbed increases linearly with the decrease in particle size of all the adsorbents. This is due to the increase in available surface area with the decrease in particle size. There exists a linear relationship between the amount adsorbed and particle size, as evidenced by the $r$-values close to unity $(\mathrm{r}-\mathrm{values}$ for $\mathrm{ECC}=0.922, \mathrm{SBC}=0.985, \mathrm{TWC}=0.894$ and $\mathrm{GUC}=0.921)$. Similar observations have been reported for the adsorption of dyes.

\subsection{Effect of ionic strength}

The effect of ionic strength on the extent removal of dye has been studied by using the flowing electrolytes i.e., $\mathrm{NaCl}, \mathrm{NaNO}_{3}$ and $\mathrm{Na}_{2} \mathrm{SO}_{4}$. increase in the percentage of removal with increase in ionic strength of electrolytes $\left(\mathrm{NaCl}, \mathrm{NaNO}_{3}\right.$ and $\left.\mathrm{Na}_{2} \mathrm{SO}_{4}\right)$ for the adsorbents indicates that the adsorption is sensitive to the changes in ionic strength, if electrostatic attraction is a significant mechanism for sorption process at low initial concentration of dye AB92). The increase in adsorption with ionic strength may be due to the compression of the thickness of the diffused electrical double layer [26]. Such compression may help the sorbent particle and sorbate species to approach each other more closely, by then the attractive forces become significant, leading to increase in adsorption. These results indicate that electrostatic attraction plays a significant role in the removal of AB92[27].

\subsection{Relative adsorption capacity}

The increasing order of relative adsorption capacity of various adsorbents compared to that of CAC (calculated from $\mathrm{Q}_{\mathrm{o}}$ values) under optimum experimental conditions is as given below:

\section{ECC $<$ TWC $<$ SBC $<$ GUC $<<$ CAC}


Among the adsorbents other than CAC, GUC has the maximum adsorption capacity, whereas ECC has the minimum adsorption capacity. The relative adsorption capacity (in terms of \%) values of various adsorbents for $\mathrm{AB} 92$ are: $\mathrm{CAC}=100, \mathrm{ECC}=33.1008, \mathrm{SBC}=36.7632, \mathrm{TWC}=33.3973$ and $\mathrm{GUC}=39.5186$. Cost wise these low cost adsorbents are cheaper than the CAC and also easily available in India (especially in Tamil $\mathrm{Nadu}$ ) as industrial waste materials.

\subsection{Thermodynamic parameters}

The thermodynamic parameters like $\Delta \mathrm{G}^{\circ}, \Delta \mathrm{H}^{\circ}$ and $\Delta \mathrm{S}^{\circ}$ have been obtained from the equilibrium constants (Table 4). The $\Delta \mathrm{G}^{\circ}$ values are found to be negative (range: -9.27 to $-24.19 \mathrm{~kJ} \mathrm{~mol}^{-1}$ ), which indicate that the adsorption process is spontaneous. The adsorptive forces are strong enough to overcome the potential barrier in solid-liquid interface [28-30]. The $\Delta \mathrm{H}^{\circ}$ values are computed to be positive (range: 7.180 to $16.37 \mathrm{k} \mathrm{J}$ $\mathrm{mol}^{-1}$ ) indicating the endothermic nature of adsorption process. The expected range of $\Delta \mathrm{H}^{\circ}$ for physisorption is 5 $-20 \mathrm{k} \mathrm{J} \mathrm{mol}^{-1}$. Since the observed values of $\Delta \mathrm{H}^{\circ}$ are within this range, it reveals that the adsorption of AB92 by adsorbent is of physisorptive in nature. The positive values of $\Delta \mathrm{S}^{\circ}$ (range: $3.47-28.55 \mathrm{~J} \mathrm{~mol}^{-1} \mathrm{~K}^{-1}$ ) indicate the increasing randomness at the solid-liquid interface during the process of adsorption. These observations are also in harmony with the results obtained in many chemical reactions. Thermodynamic parameters indicate that the adsorption process is spontaneous, endothermic and physisorptive in nature.

\subsection{Desorption}

The studies of $\mathrm{AB} 92$ dye loaded adsorbents have been tested with DD water and eluents like $\mathrm{HCl}$, $\mathrm{HNO}_{3}, \mathrm{H}_{2} \mathrm{SO}_{4}, \mathrm{CH}_{3} \mathrm{COOH}$ and $\mathrm{NaOH}$. The values of percentage of desorption with DD water and eluents $(0.5$ $\mathrm{N}$ ) are reported in Table 5. Among these, $\mathrm{HNO}_{3}$ is found to be an effective eluent. The extent of desorption increases exponentially with the increase in concentration of $\mathrm{HNO}_{3}$ and becomes constant. The optimum concentration of $\mathrm{HNO}_{3}$ for effective desorption of $\mathrm{AB} 92$ from $\mathrm{AB} 92$ loaded adsorbents is fixed as $0.5 \mathrm{~N}$.

The adsorption capacity of regenerated adsorbent was checked for three cycles and it is found to be less compared to the original samples, but it is also suitable for removal of AB92 from dilute solutions. This will again definitely lower the cost of removal of AB92 and effluent treatment process. ECC, SBC, TWC and GUC could be used as low cost adsorbents as alternative to CAC for the removal of dyes in general and $\mathrm{AB} 92$ in particular.

\section{Conclusions}

Plant materials from agriculture waste is successfully utilized as an adsorbents for the removal of AB92 by Batch adsorption method. The percentage removal of AB92 increases with decrease in initial concentration and particle size and increases with increase in contact time, initial $\mathrm{pH}$ and dose. The adsorption data are modeled with adsorption isotherms and first order kinetic equations. Adsorption process obeys Langmuir isotherm and Lagergren equation and proceeds with first order kinetics, with intra particle diffusion as one of the rate determining steps. The present study concludes that ECC, SBC, TWC and GUC could be employed as low cost adsorbents as alternative to CAC for the removal of colour and dyes from water and wastewater in general and for the removal of AB92 in particular.

\section{Acknowledgement}

The authors thank the Management of Ayya Nadar Janaki Ammal College for providing necessary research fescility for my work.

\section{References}

[1] C. Moreno-Castilla, Adsorption of organic molecules from aqueous solutions on carbon materials, Carbon, 42 (2004) 83-94.

[2] S. Wang, Z.H. Zhu, A. Coomes, F. Haghseresht and G.Q. Lu, The physical and surface characteristics of activated carbons and the adsorption of methylene blue from wastewater, Colloid Interface Sci., 284 (2005) 440-446.

[3] Y. Leon, C.A. Leon, J.M. Solar, V. Calemma, L.R. Radovic, Evidence for protonation of basal plane sites on carbon, Carbon, 30 (1992) 797-811

[4] B. Boulinguiez, P. Le Cloirec and D. Wolbert, Revisiting the d etermination of Langmuir parameters application to Tetrahydrothiophene adsorption onto activated Carbon, Langmuir, 24 (2008) 6420-6424.

[5] G. McKay, H.S. Blair and J. Gardner, Adsorption of dyes on chitin.I. Equilibrium studies, J Applied Poly. Sci., 27 (2003) $3043-$ 3057.

[6] I.D. Mall, V.C. Srivastava, N.K. Agarwal and I.M. Mishra, Adsorption removal of malachite green dye from aqueous solution by bagasse fly ash and activated carbon- kinetic study and equilibrium isotherm analyses, Colloids Surf. A, 264 (2004) 17-28.

[7] T.H. Shek, A. Ma, V.K.C. Lee and G. McKay, Kinetics of zinc ions removal from effl uents using ion exchange resin, Chem. Eng J., 146 (2009) 63-70.

[8] A. Günay, E. Arslankaya and I. Tosun, Lead removal from aqueous solution by natural and pretreated clinoptilolite: Adsorption equilibrium and kinetics, J. Hazard. Mater., 146 (2007) 362-371.

[9] R.P. Han, P. Han, Z.H. Cai, Z.H. Zhao and M.S. Tang, Kinetics and isotherms of Neutral Red adsorption on peanut husk, J Environ. Sci., 20 (2008) 1035-1041. 
[10] J. Vymazal, Constructed wetlands with horizontal subsurface fl ow in the Czech Republic: Two long-term case studies, Desal. Water Treat., 4 (2009), 40-44.

[11] K.S. Low, C.K. Lee and L.L. Heng, Sorption of basic dyes by Hydrillaverticillata, Environ. Technol., 14 (1993) 115-124.

[12] A. Aguedacha, S. Brosillonb, J. Morvanb and E. Lhadi, Photo-catalytic degradation of azo-dyes reactive black 5 and reactive yellow 145 in water over a newly deposited titanium dioxide, Appl. Catal. B, 57 (2005) 55-62.

[13] V. Gomez, M.S. Larrechi and M.P. Callao, Kinetic and adsorption study of acid dye removal using activated carbon, Chemosphere, 69 (2007) 1151-1158.

[14] R.M. Gong, Y. Ding, M. Li, C. Yang, H.J. Liu and Y.Z. Sun, Utilization of powdered peanut hull as biosorbent for removal of anionic dyes from aqueous solution, Dyes Pigm., 64 (2005) 187-192.

[15] K.G. Bhattacharyya and A. Sarma, Adsorption characteristics of the dye, brilliant green, on neem leaf powder, Dyes Pigm., 57 (2005) 211-222.

[16] J.F. Osma, V. Saravia, J.L. Toca-Herrera and S.R. Couto, Sun flower seed shells: a novel and effective low-cost adsorbent for the removal of the diazo dye reactive black 5 from aqueous solutions, J. Hazard. Mater., 147 (2007) 900-905.

[17] S.H. Chien and W.R. Clayton, Application of Elovich Equation to the Kinetics of Phosphate Release and Sorption in Soils, Soil Sci. Soc. Am. J., 44 (1980) 265-268.

[18] W.J. Weber and J.C. Morris, In: W. W. Eckenfelder, (Ed.), Advances in water pollution research, Pergamon Press, Oxford, 1964.

[19] B.H. Hameed, A.T. Mohd Din and A.L. Ahmad, Adsorption of methylene blue onto bamboo-based activated Carbon: kinetics and equilibrium studies, J. Hazard. Mater., 141 (2007) 819-825.

[20] K.V. Kumar, Adsorption isotherms for basic dyes onto low cot adsorbents, Res. J. Chem. Environ., 6 (2002) 61-65

[21] D. Kavitha and C. Namasivayam, Experimental and kinetic studies on methylene blue adsorption by coir pith carbon, B ioresour. Technol., 98 (2007) 14-21.

[22] V. Ponnusami, S. Vikram and S.N. Srivastava, Guava (Psidium guajava) leaf powder: Novel adsorbent for removal of methy- lene blue from aqueous solutions, J. Hazard. Mater., 152 (2008) 276-286.

[23] C. Namasivayam and S. Senthil Kumar, 'Recycling of Industrial Solid waste for the Removal of Mercury (II) by Adsorption Process In: Advances in Environmental Science', C.S.P. Iyer(Ed.), Educ. Book Publ. \& Dist., New Delhi, 1997, p.375.

[24] A.E. Nemr, O. Abdelwahab, A. El-Sikaily and A. Khaled, Removal of direct blue-86 from aqueous solution by new activated carbon developed from orange peel, J. Hazard. Mater., 161 (2009) 102-110.

[25] S. Ekici, Y. Isikver, N. Sahiner and D. Saraydin, Adsorption of some textile dyes onto crosslinked poly(N-vinylpyrrolidone), Adsorpt. Sci. Technol., 21 (2003) 651-659.

[26] I.D. Mall, V.C. Srivastava and N.K. Agarwal, Removal of Orange-G and Methyl Violet dyes by adsorption onto bagasse fly ashkinetic study and equilibrium isotherm analyses, Dyes Pigm., 69 (2006) 210-223.

[27] C. Broto, S.I. Oei, S. Wang and H.M. Ang, Surfactant modified barley straw for removal of acid and reactive dyes from aqueous solution, Bioresour. Technol., 100 (2009) 4292-4295.

[28] G. Atun and G. Hisarli, Adsorption of carminic acid, a dye on glass powder, J. Chem. Eng. Data, 95 (2003) 241-249.

[29] P.K. Grover and R.L. Ryall, Critical appraisal of salting-out and its implications for chemical and biological sciences, Chem. Rev., 105 (2005) 1-10.

[30] A. Ozer and G. Dursun, Removal of methylene blue from aqueous solution by dehydrated wheat bran carbon, J. Hazard. Mater., 146 (2007) 262-269.

Table captions

1. Effect of process parameter on the extent of removal of $\mathrm{AB} 92$ by various adsorbents at $30^{\circ} \mathrm{C}$

2. Freundlich and Langmuir parameters of adsorption isotherms for the removal of AB92 by various adsorbents at $30^{\circ} \mathrm{C}$

3. Statistical results of the application of the kinetic equations and models for the removal of AB92 by various adsorbents at $30^{\circ} \mathrm{C}$

4. Thermodynamic parameters for the adsorption AB92

Table 1

\begin{tabular}{||l|l|c|c|c|c|c|}
\hline \hline \multirow{2}{*}{ Model } & \multirow{2}{*}{ Parameter } & \multicolumn{5}{|c|}{ Adsorbents } \\
\cline { 3 - 7 } & & CAC & EC & SB & TW & GL \\
\hline \hline \multirow{3}{*}{$\begin{array}{l}\text { Freundlich } \\
\text { isotherm }\end{array}$} & K-value & 0.289 & 0.149 & 0.158 & 0.139 & 0.157 \\
\cline { 2 - 7 } & Slope (1/n) & 0.006 & 0.003 & 0.003 & 0.003 & 0.003 \\
\cline { 2 - 7 } & $\begin{array}{l}\text { Correlation } \\
\text { co-efficient (r) }\end{array}$ & 0.827 & 0.4658 & 0.6804 & 0.6197 & 0.3847 \\
\hline \multirow{3}{*}{$\begin{array}{l}\text { Langmuir } \\
\text { isotherm }\end{array}$} & $\mathbf{Q}_{\mathbf{o}}$ & 0.5734 & 0.1633 & 0.0458 & 0.1739 & 0.1795 \\
\cline { 2 - 7 } & $\mathbf{B}$ & 2.0204 & 0.2539 & 2.0879 & 0.1299 & 0.0338 \\
\cline { 2 - 8 } & $\begin{array}{l}\text { Correlation } \\
\text { co-efficient (r) }\end{array}$ & 0.9979 & 0.9829 & 0.8837 & 0.9989 & 0.9985 \\
\cline { 2 - 8 } & $\mathbf{R}_{\mathbf{L}}$ & 0.009843 & 0.1645 & 0.02131 & 0.2779 & 0.0417 \\
\hline \hline
\end{tabular}

Figure captions

1. Effect of initial concentration of acid blue 92 by various adsorbents

2. Freundlich isotherm of adsorption of acid blue 92 by various adsorbents

3. Langmuir isotherm of adsorption of acid blue 92 by various adsorbents

4. Effect of contact time of adsorption of acid blue 92 by various adsorbents

5. Natarajan kalaf kinetic equation of adsorption $\mathrm{f}$ acid blue 92 by various adsorbents 
6. Lagergren kinetic equation of adsorption of acid blue 92 by various adsorbents

7. Bhatacharya venkobachar kinetic equation of adsorption f acid blue 92 by various adsorbents

8. Intra particle diffusion of adsorption of acid blue 92 by various adsorbents

9. Effect of dose of adsorbent of adsorption of acid blue 92 by various adsorbents

10. Effect of $\mathrm{pH}$ of adsorbent of adsorption of acid blue 92 by various adsorbents

Table 2

\begin{tabular}{|l|l|l|l|l|l|l|}
\hline \multirow{3}{*}{ Process Parameter varied } & \multicolumn{5}{l|}{ Adsorbents } \\
\cline { 2 - 7 } & Parameter & CAC & EC & SB & TW & GL \\
\hline \multirow{3}{*}{ Initial concentration } & Optimum & $50 \mathrm{ppm}$ & $20 \mathrm{ppm}$ & $22 \mathrm{ppm}$ & $20 \mathrm{ppm}$ & $23 \mathrm{ppm}$ \\
\cline { 2 - 7 } & $\% \mathrm{R}$ & 88 & 92.8 & 89.6 & 92.7 & 93.3 \\
\hline \multirow{2}{*}{ Contact time } & Optimum & $40 \mathrm{~min}$. & $60 \mathrm{~min}$. & $60 \mathrm{~min}$. & $30 \mathrm{~min}$. & $45 \mathrm{~min}$. \\
\cline { 2 - 8 } & $\% \mathrm{R}$ & 87 & 96 & 91 & 89 & 73 \\
\hline \multirow{2}{*}{ Dose } & Optimum & 200 & 120 & 180 & 150 & 160 \\
\cline { 2 - 8 } & $\% \mathrm{R}$ & 90 & 90 & 82 & 83 & 53 \\
\hline \multirow{2}{*}{ Initial pH } & Optimum & 5 & 4.6 & 5.2 & 5.1 & 5.3 \\
\cline { 2 - 8 } & $\% \mathrm{R}$ & 89 & 96 & 86 & 78 & 82 \\
\hline \multirow{2}{*}{ Particle size } & Optimum & 140 & 150 & 120 & 120 & 150 \\
\cline { 2 - 7 } & $\% \mathrm{R}$ & 92 & 90 & 88 & 87 & 82 \\
\hline
\end{tabular}

Table 3

\begin{tabular}{|c|c|c|c|c|c|}
\hline \multirow{2}{*}{ Parameter } & \multicolumn{5}{|c|}{ Adsorbents } \\
\hline & $\mathrm{CAC}$ & EC & SB & TW & GL \\
\hline \multicolumn{6}{|c|}{ I. Natarajan and Khalaf equation } \\
\hline $10^{2} \mathrm{k}$ & 0.1303 & 0.2303 & 0.2303 & 0.6909 & 0.2303 \\
\hline r-value & 0.7161 & 0.3066 & 0.2950 & 0.5814 & 0.4593 \\
\hline \multicolumn{6}{|c|}{ II.Lagergren equation } \\
\hline $10^{2} \mathrm{k}$ & 0.3473 & 0.4606 & 0.6909 & 0.9212 & 0.2303 \\
\hline r-value & 0.6148 & 0.2258 & 0.2000 & 0.5486 & 0.4494 \\
\hline \multicolumn{6}{|c|}{ III.Bhattacharya and Venkobachar equation } \\
\hline $10^{2} \mathrm{k}$ & 0.1736 & 0.4606 & 0.6909 & 0.9212 & 0.2303 \\
\hline r-value & 0.7085 & 0.2258 & 0.2000 & 0.5486 & 0.4494 \\
\hline \multicolumn{6}{|c|}{ IV.Intra particle diffusion model } \\
\hline $10^{2} \mathrm{k}_{p}$ & 1.2 & 0.6909 & 0.1152 & 0.9212 & 0.9212 \\
\hline Intercept & 0.478 & 0.1270 & 0.1790 & 0.1240 & 0.1610 \\
\hline r-value & 0.6611 & 0.4848 & 0.5404 & 0.4593 & 0.3899 \\
\hline \multicolumn{6}{|c|}{ V. $\log (\%$ removal) vs $\log$ (time) } \\
\hline $10^{2}$ Slope & 20.2 & 0.102 & 0.119 & 0.237 & 0.166 \\
\hline Intercept & 89.09 & 71.65 & 65.70 & 82.78 & 66.78 \\
\hline r-value & 0.7589 & 0.3795 & 0.3535 & 0.6442 & 0.5079 \\
\hline
\end{tabular}

\begin{tabular}{l|l} 
Table 4 & Table 4.4: Thermodynamic parameters for the adsorption AB \\
\cline { 2 - 2 } &
\end{tabular}

\begin{tabular}{|c|c|c|c|}
\hline Adsorbents & $\Delta \mathrm{G}^{0}\left(\mathrm{~kJ} \mathrm{~mole}^{-1}\right)$ & $\Delta \mathbf{H}^{0}\left(\mathrm{~kJ} \mathrm{~mole}^{-1}\right)$ & $\Delta \mathbf{S}^{0}\left(\mathrm{~J} \mathrm{~mole}^{-1} \mathrm{~K}^{-1}\right)$ \\
\hline CAC & -24.19 & 16.37 & 25.86 \\
\hline EC & -8.718 & 7.180 & 10.16 \\
\hline SB & -11.45 & 8.710 & 28.55 \\
\hline TW & -16.93 & 14.78 & 3.47 \\
\hline GL & -9.27 & 6.679 & 13.10 \\
\hline
\end{tabular}




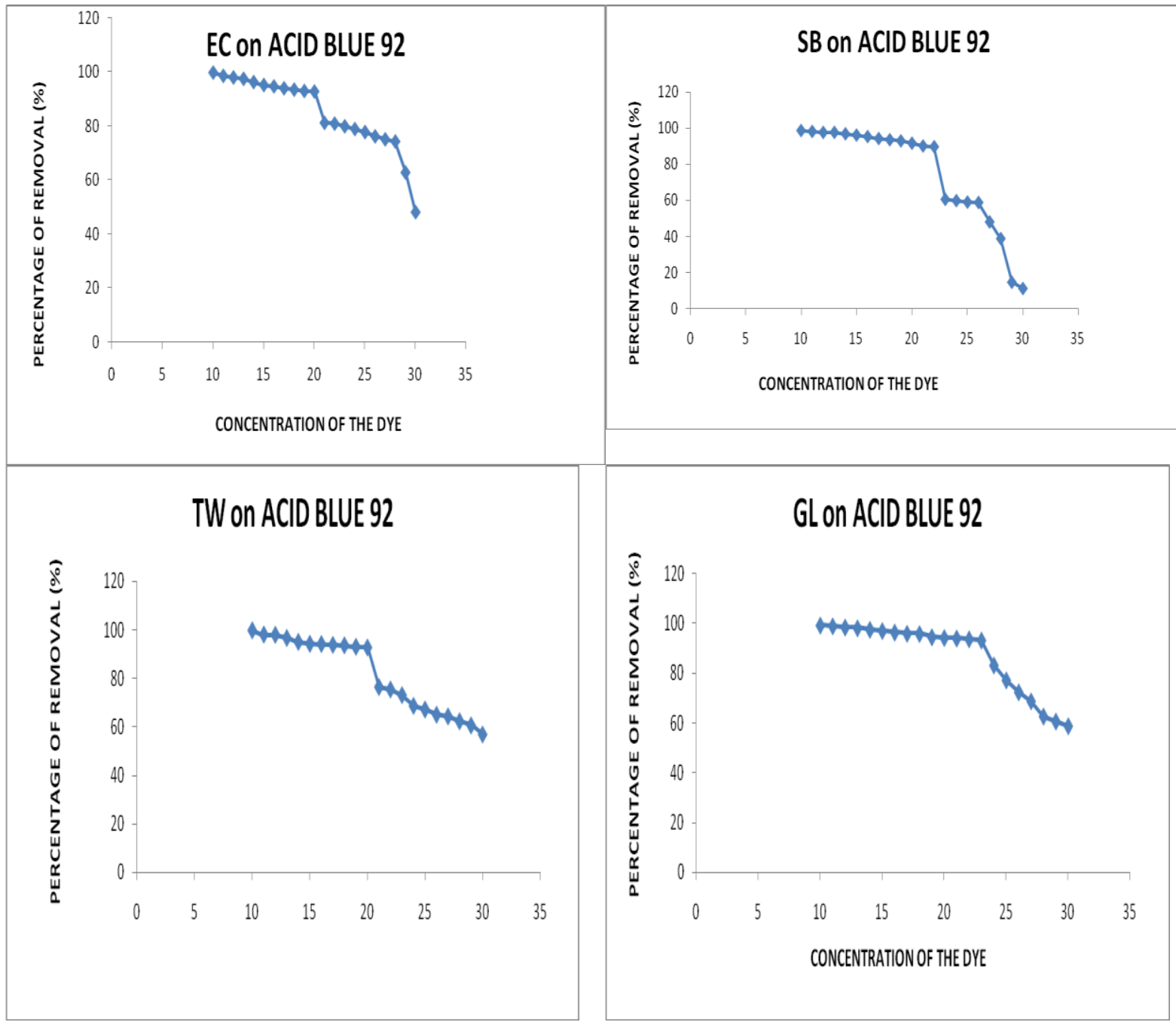

Fig. 1
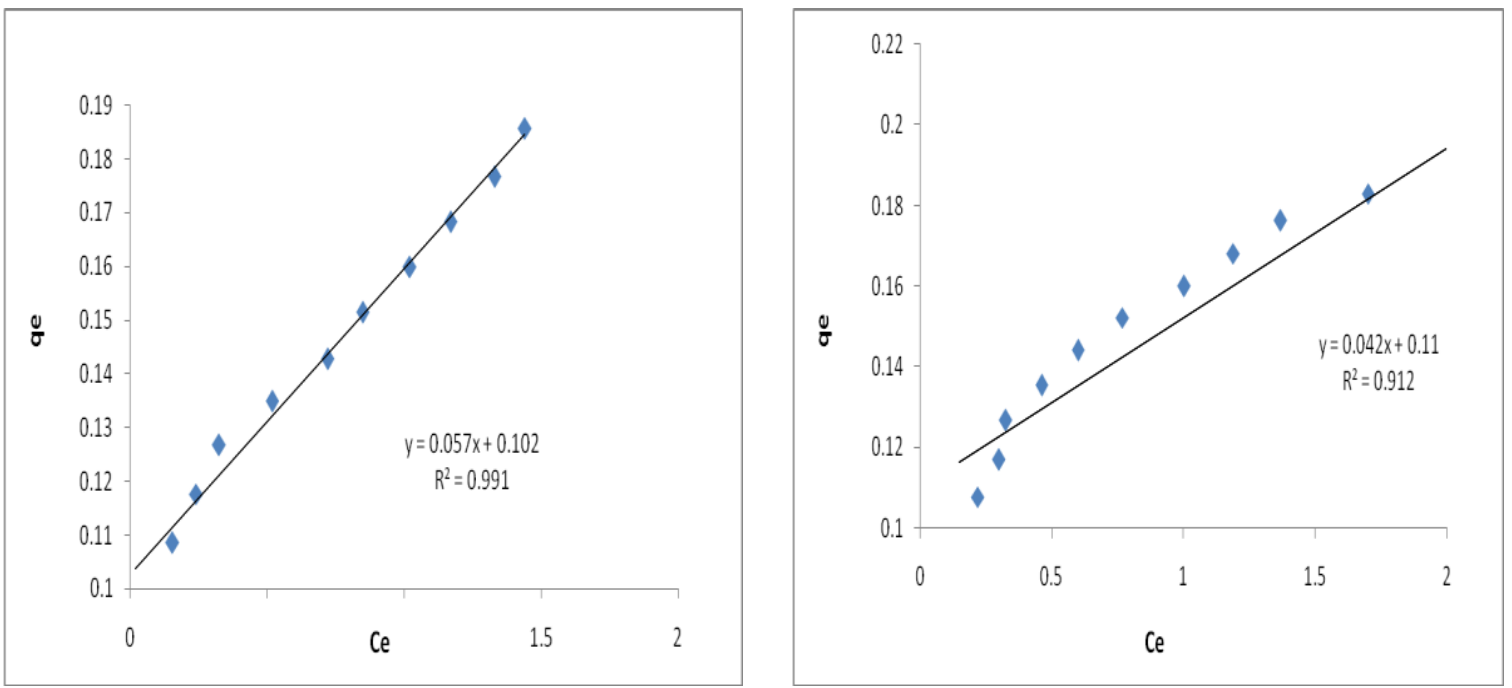

Fruindlich Isotherm ACIDBLUE 92 bY EC

Fruindlich Isotherm cevs qe 


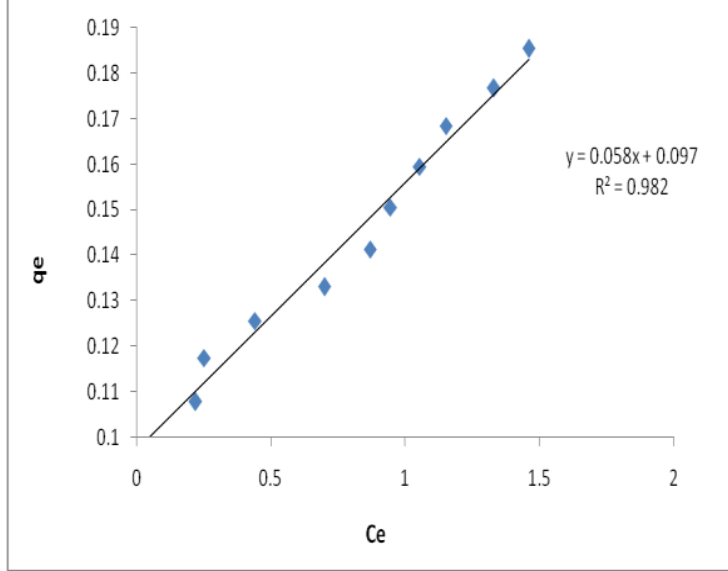

Fruindlich Isotherm ACID BLUE 92 by TW cevs qe

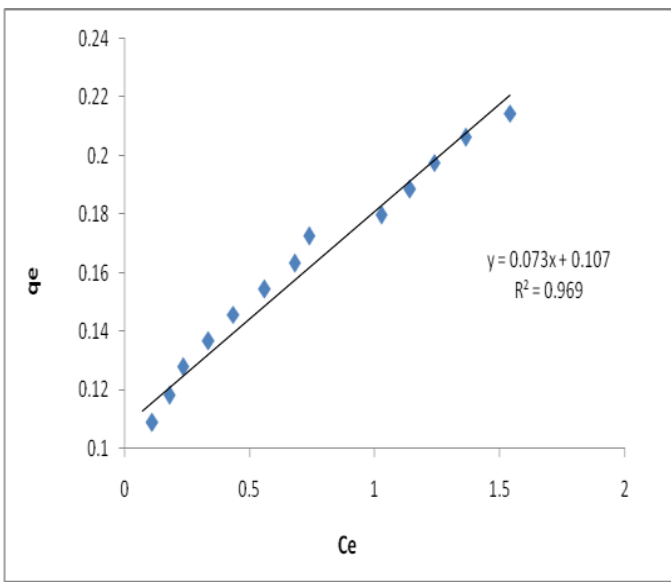

Fruindlich Isotherm ACIDBLUE 92 bY $G$ cevs qe

Fig. 2

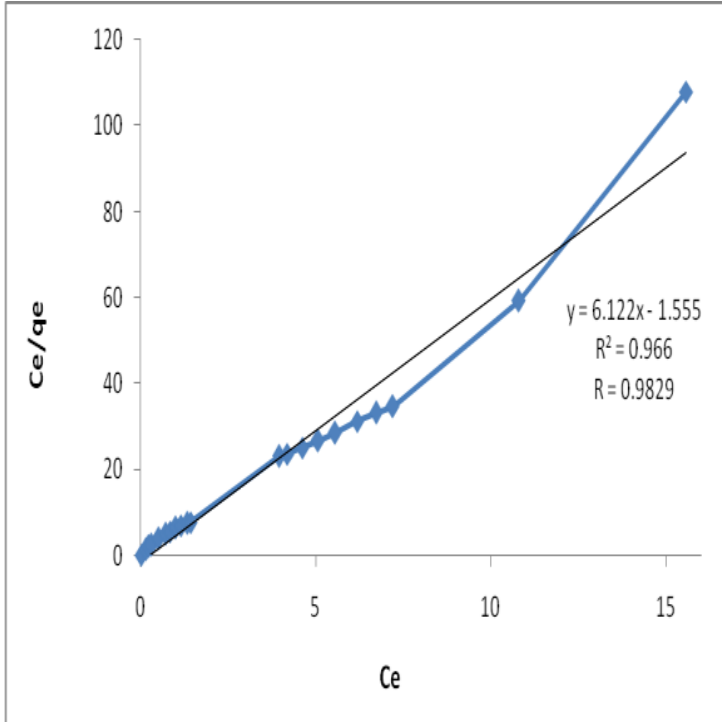

Langmuirisotherm ACIDBLUE 92 bY EC cevs celqe
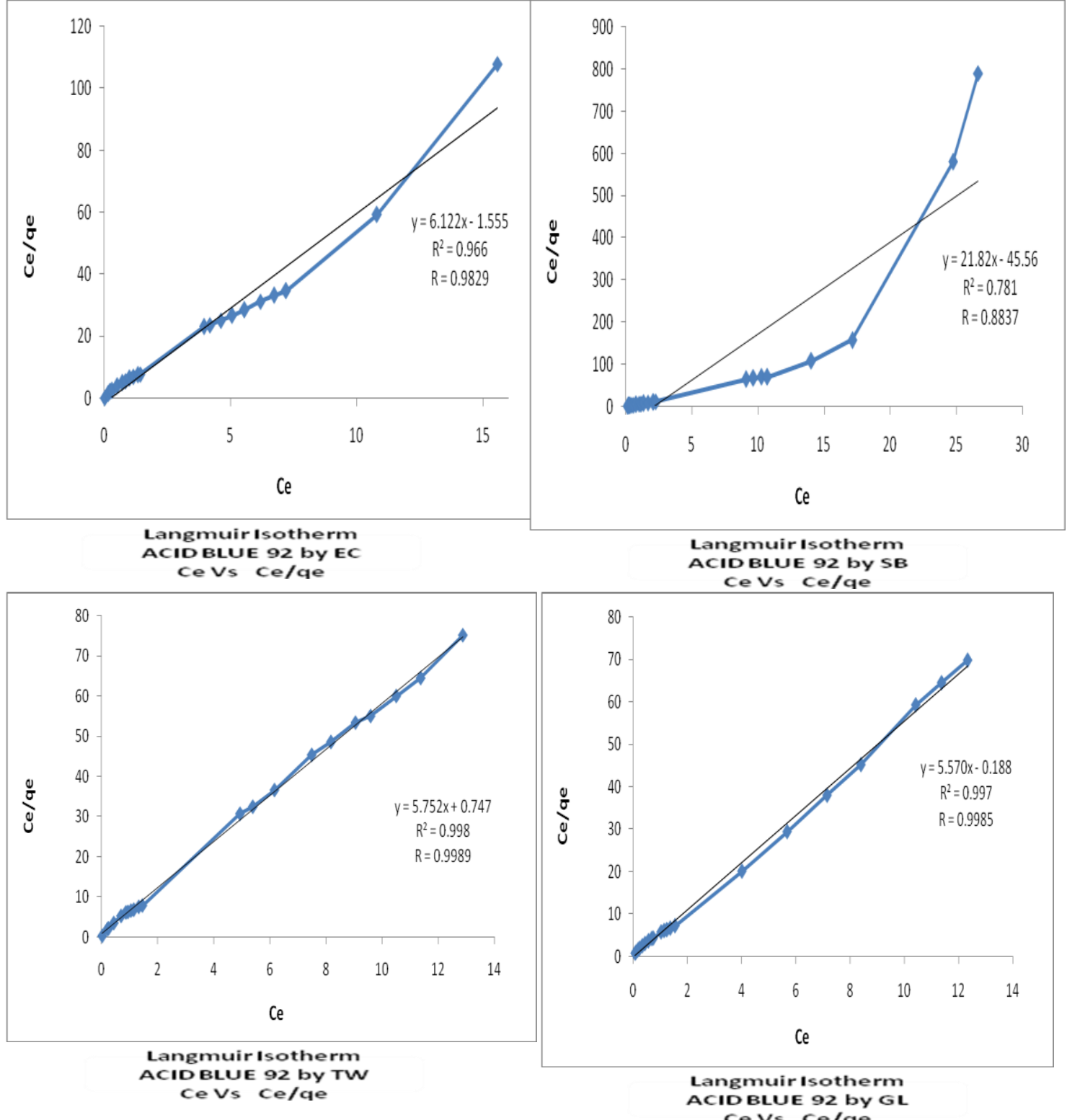

Langmuirisotherm cevs celae ACIDBLUE 92 by GL

Fig.. 3 

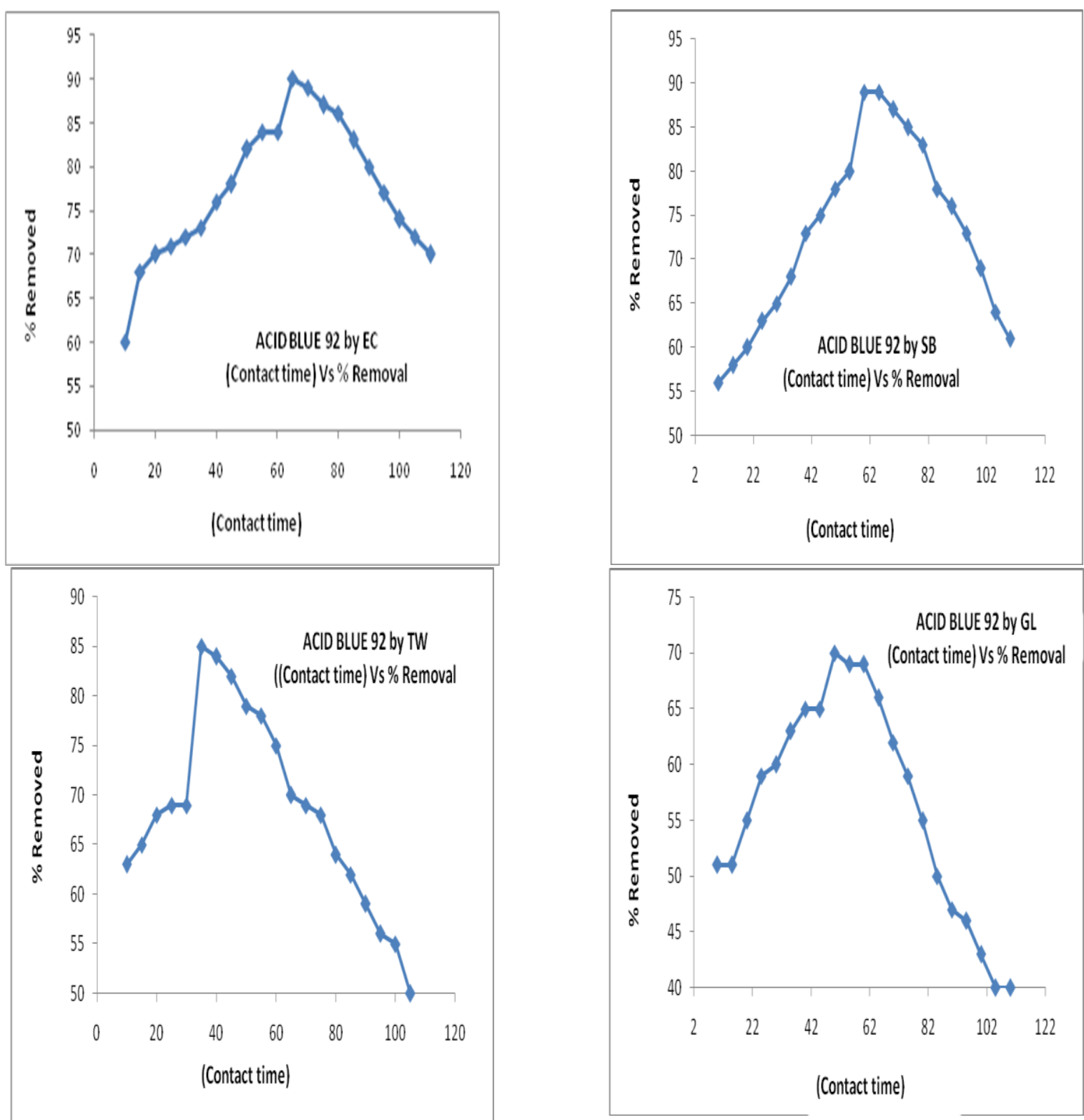

Fig. 4

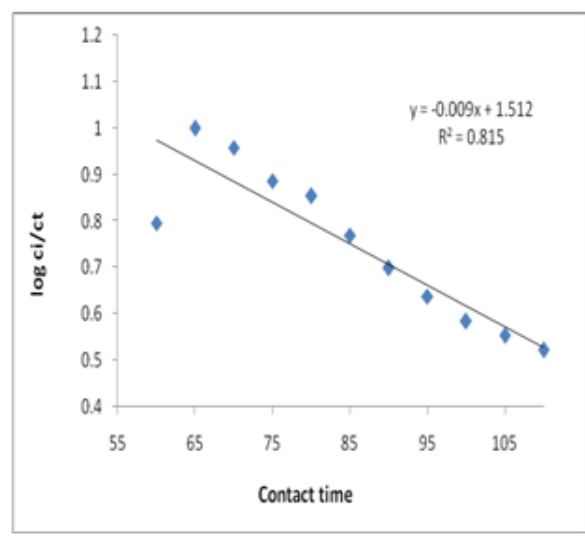

Natarajan and Khal af equation

ACID BLUE 92 bY EC

contact time Vs log Ci/Ct

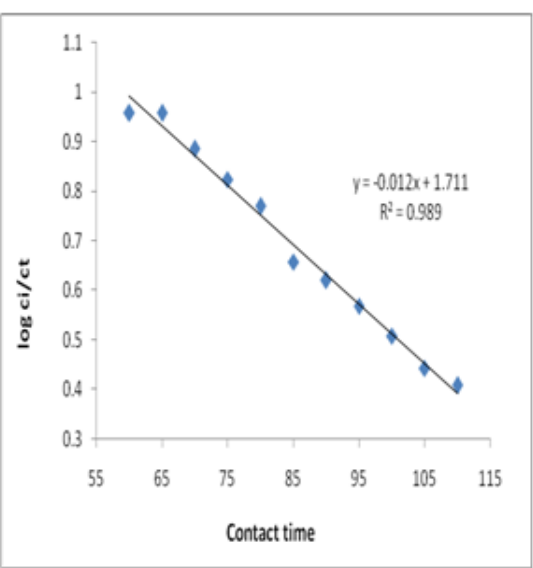

Natarajan and Khalaf equation

ACIDBLUE 92 by SB

contact time Vs log Ci/ct 


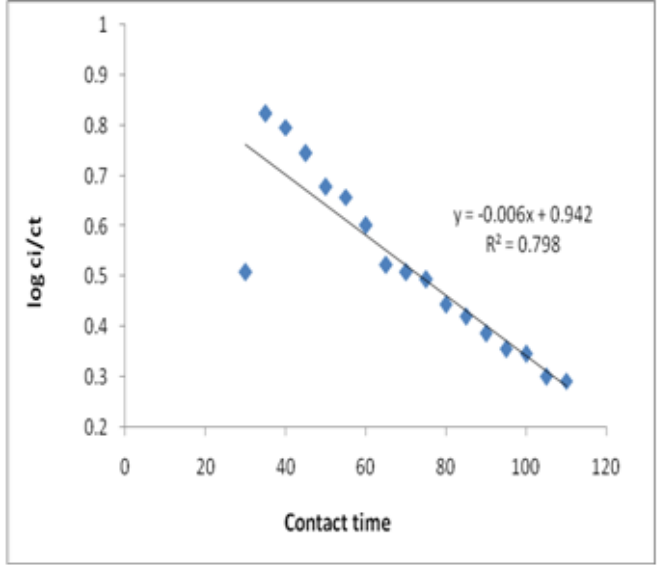

Natarajan and Khal af equation ACID BLUE 92 by TW contact time Vs log $\mathrm{Ci} / \mathrm{Ct}$

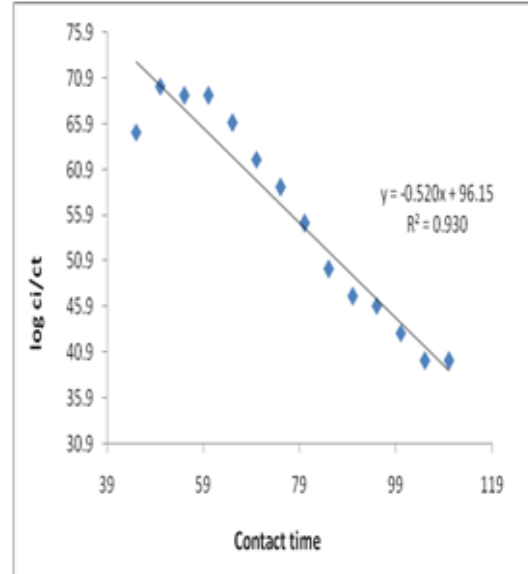

Natarajan and Khalaf equation ACIDBLUE 92 by $6 L$

contact time Vs $\log \mathrm{Ci} / \mathrm{C}$

Fig. 5
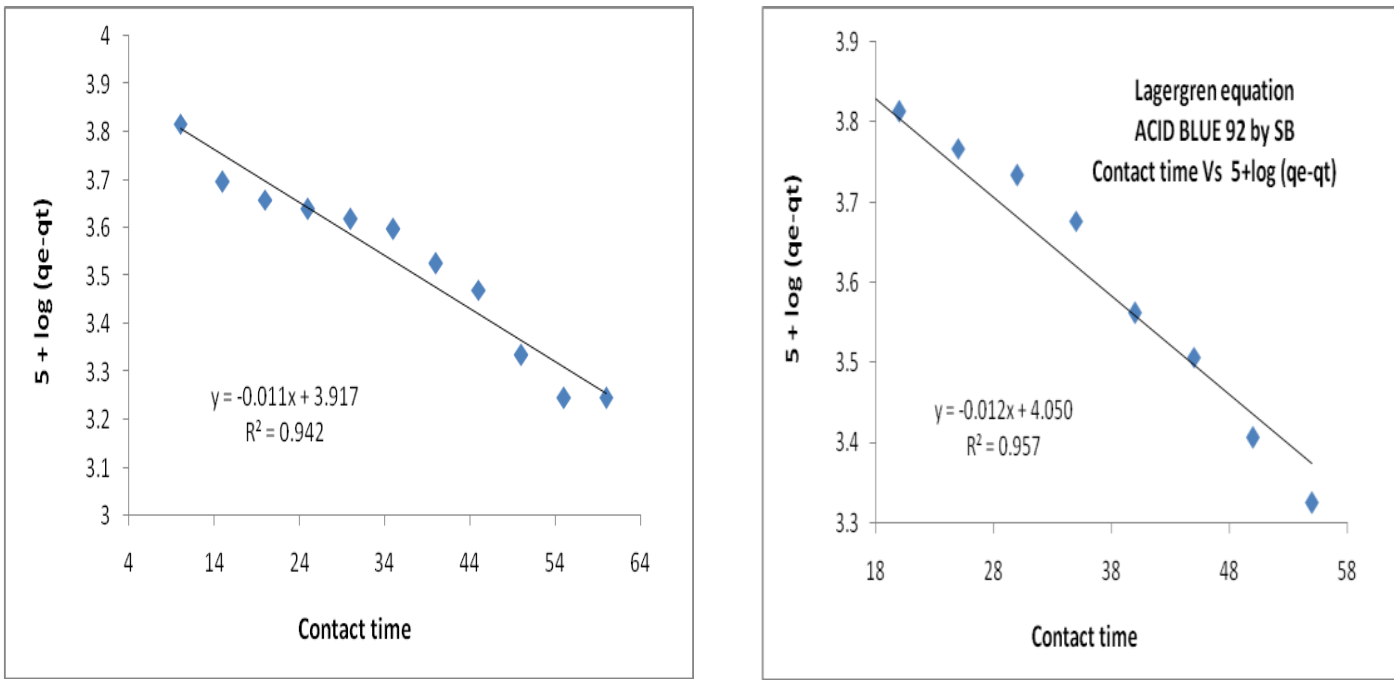

Lagergren equation

Lagergren equation

ACIDBLUE 92 by EC
act time Vs $5+\log$ (qe-qt)

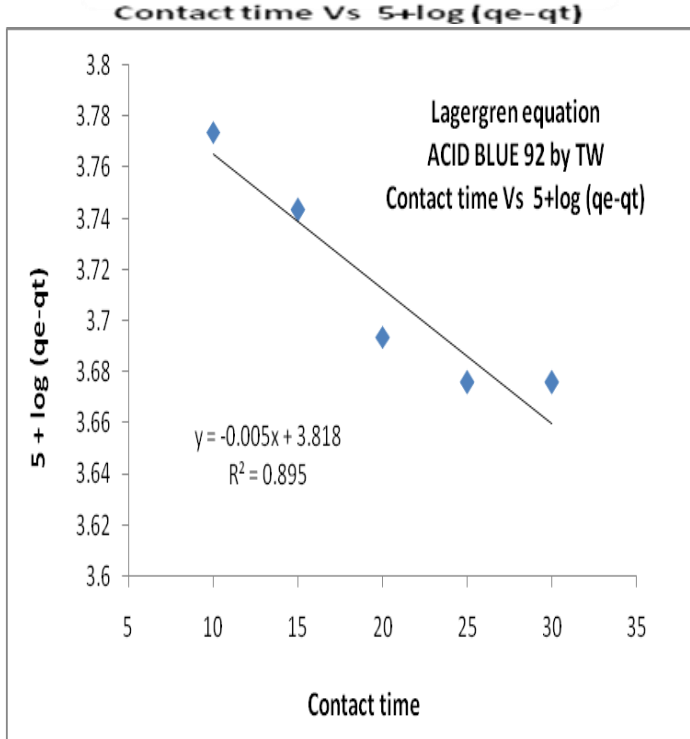

contact time Vs $5+\log (q e-q t)$

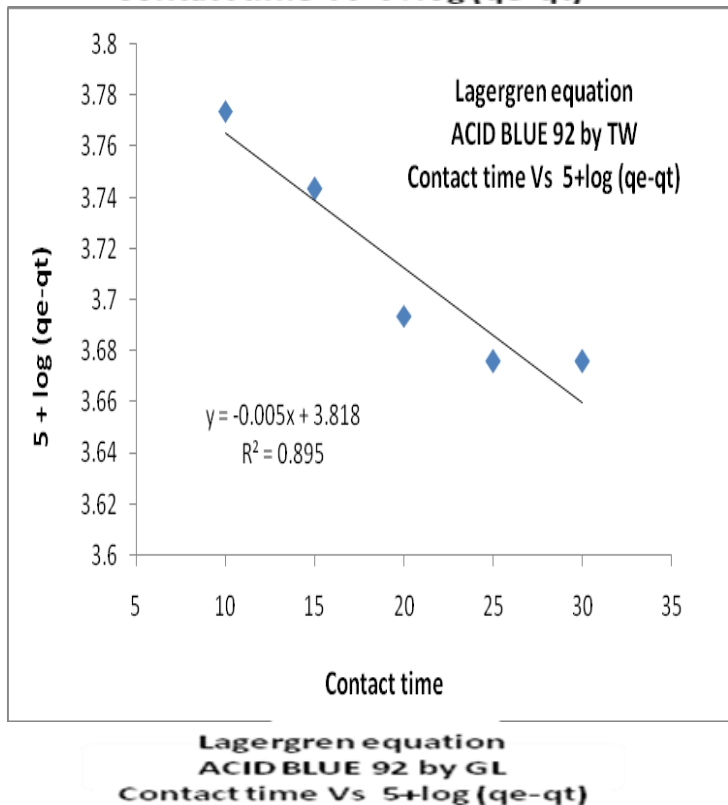

AcID B contact time VS $5+\log$ (qe-qt)

Fig. 6 

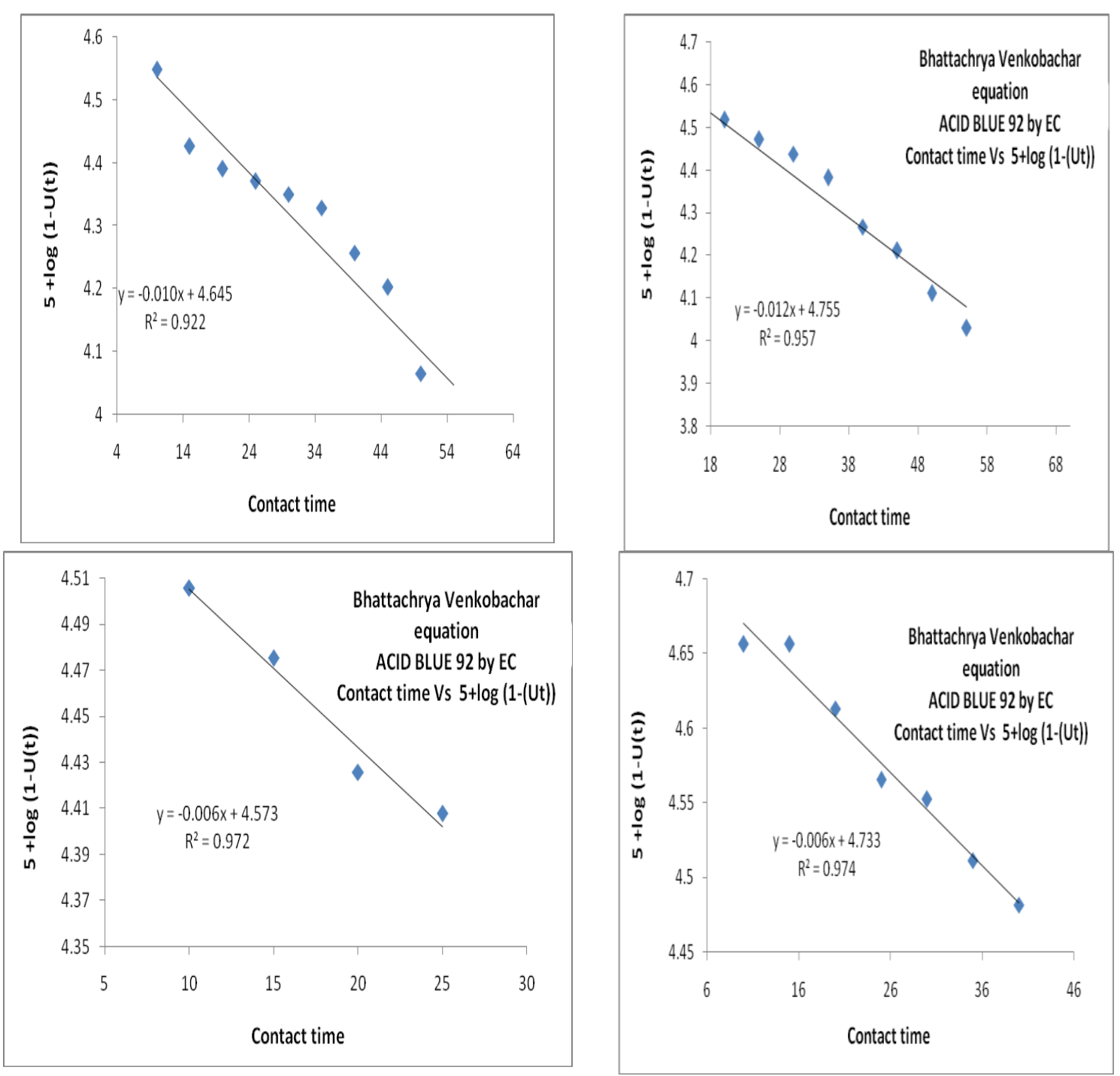

Fig. 7
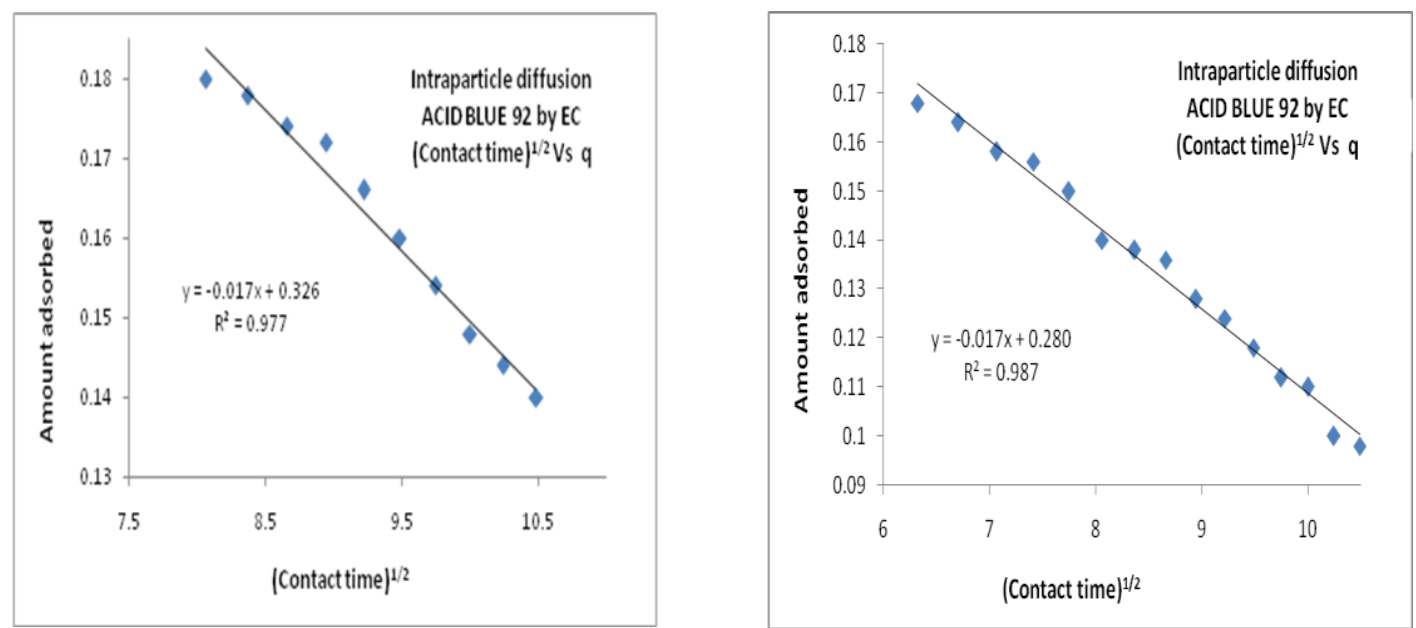

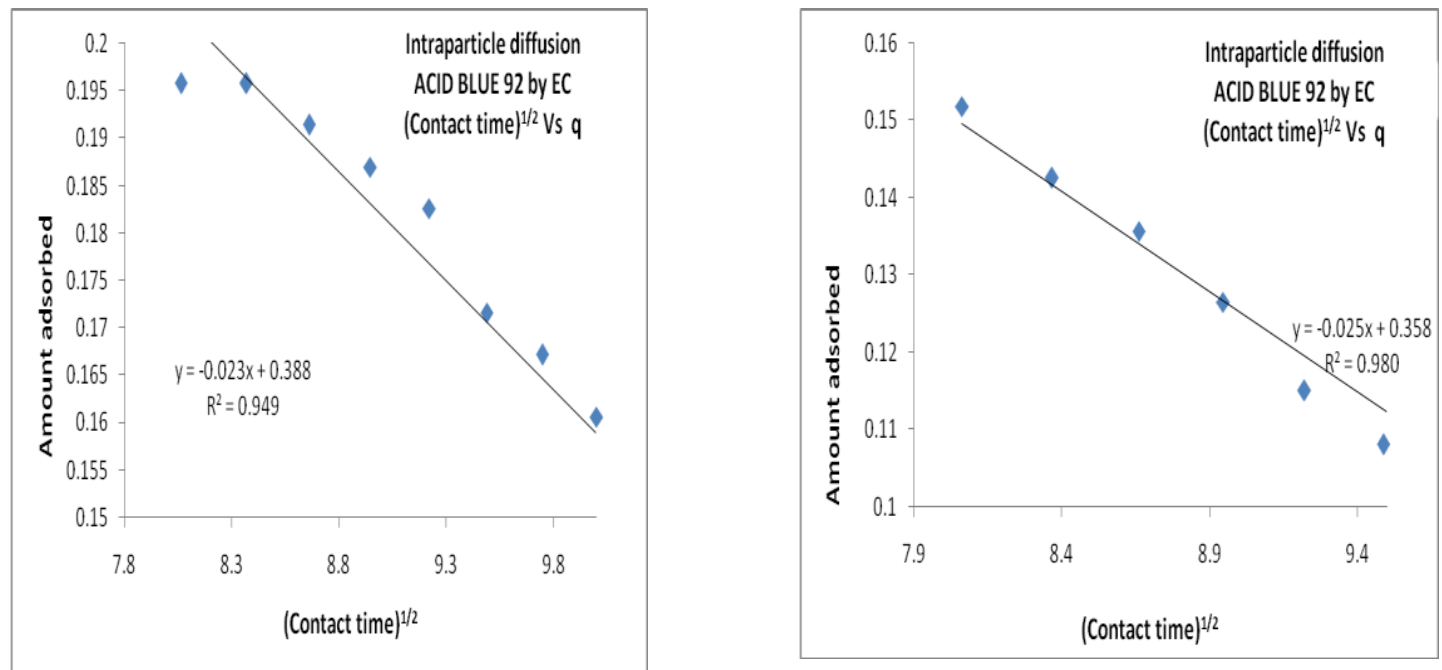

Fig. 8
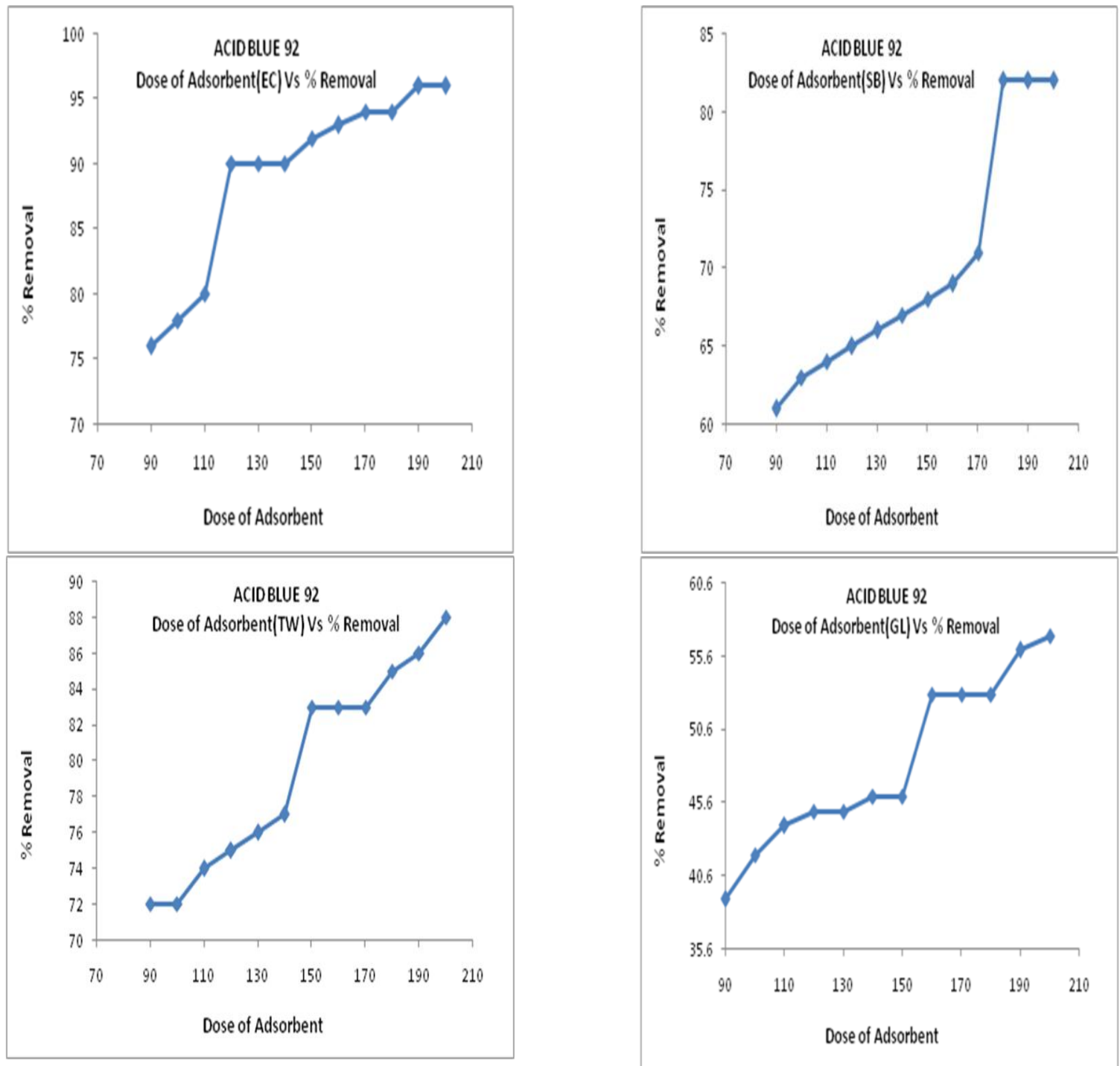

Fig. 9 

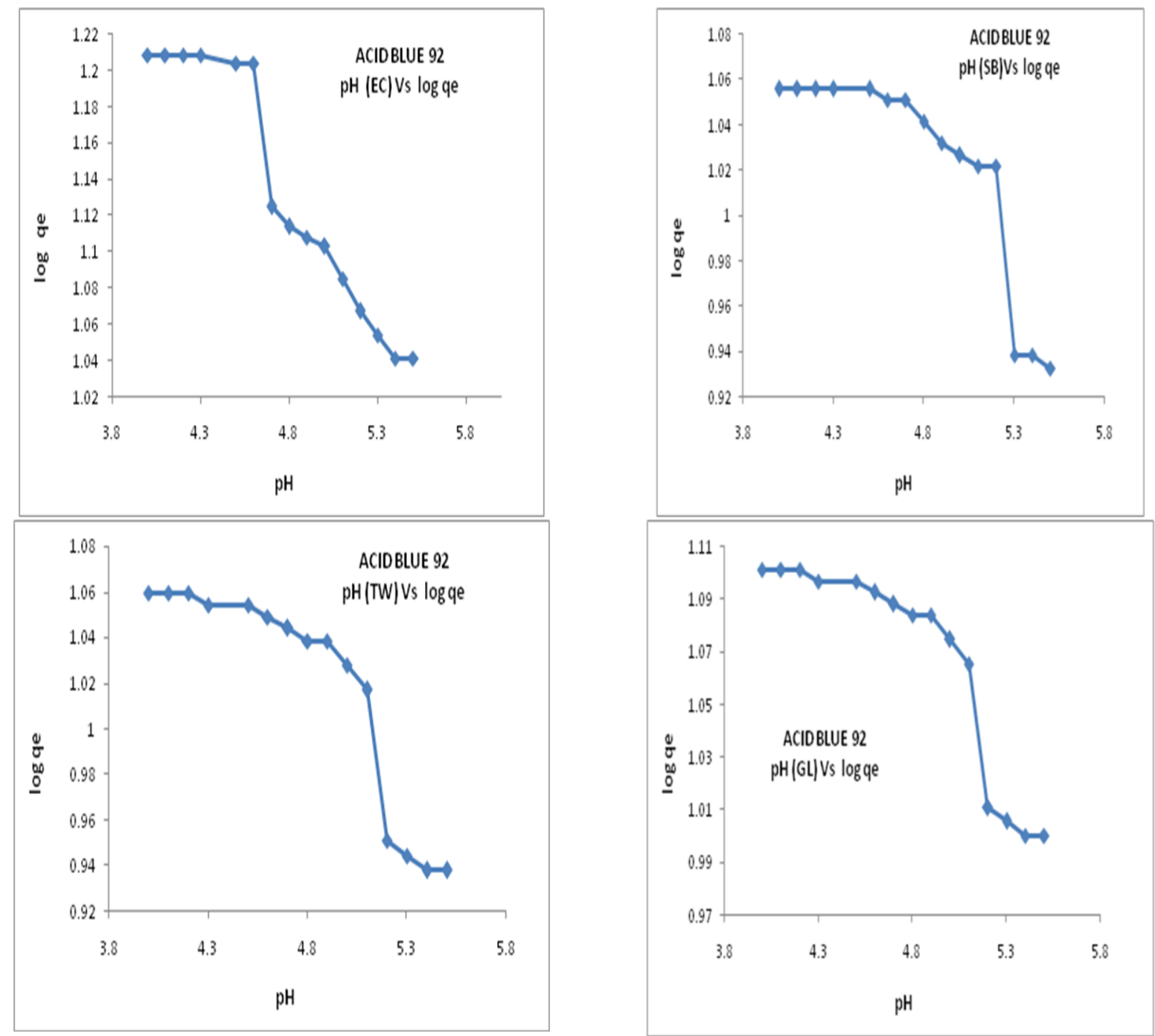

Fig. 10 